\title{
FIBROCYSTIC DISEASE OF THE FRONTAL BONE (PAGET'S OSTEITIS)
}

\author{
BY \\ LT.-Col. R. E. Wright, C.I.E., I.M.S. \\ PROFESSOR OF OPHTHALMOLOGY AND SUPERINTENDENT, GOVERNMENT \\ OPHTHALMIC HOSPITAL, MADRAS, INDIA
}

THE case which is briefly recorded here is of interest both from a surgical and pathological point of view. A Hindu girl aged 20 years presented herself at hospital on March 11, 1935, with a diffuse protuberance of the left frontal region, a soft cystic tumour projecting from beneath the left supra-orbital rim, and proptosis of left eye. She said that the left side of the brow had become more prominent gradually during the last ten years. She maintained that the swelling of the eye had only become really marked within the week. The globe was pushed downwards. Its movements were not impaired except in an upward direction, and the vision was normal. The photograph gives a better idea of the condition than further description (Fig. 1). The fluctuating tumour was not pulsatile; mucocele was anticipated and it was explored. Serosanguineous fluid was obtained. An X-ray picture revealed a " nigger wool" skull. The reduced X-ray positives give an idea of the condition (Fig. 3). The proptosis required attention and a tarsorrhaphy was done, subsequent to the aspiration of 250 c.c. of sero-sanguineous fluid from the cyst. It filled again. It was decided to cut down on the cyst through the left brow, remove a portion of the frontal bone, drain the cyst from the temporal side and let the skin fall in. This was carried out. The cyst was lined for the most part with a smooth serous membrane. It roughly corresponded to what might have been an expanded frontal sinus, but presumably was not. The periosteum at the orbital rim was continuous with the membranous cyst wall or capsule which intervened between orbital contents and the cyst cavity. 'The roof of the cyst was somewhat granular to the examining finger and inclined to bleed. With fingers in the cystic cavity and the thumb on the frontal region one felt a thinned out edge at the orbital rim, but three-fourths of an inch back of this the bone was an inch thick. The periosteum was stripped from the orbital rim which was then cut back for about an inch. It cut readily with a scalpel and was of a gritty consistency like cuttlefish bone. The cavity was drained and the periosteal flap and skin allowed to fall in.

A photograph a year later (Fig. 2) shows that the large cavity had filled up and become lined throughout with skin leaving a 


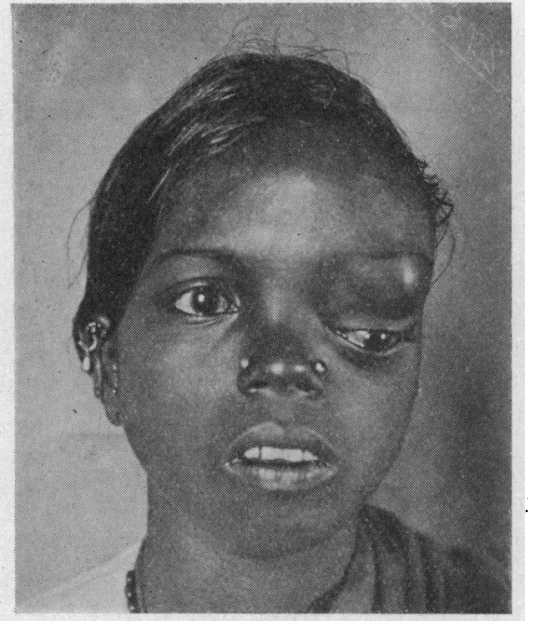

FIG. 1.

Showing the appearances on March 14, 1935.

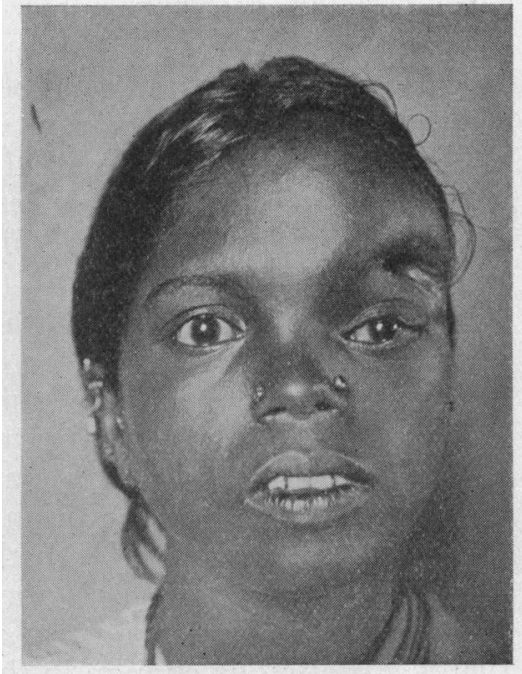

FIG. 2 .

Showing the appearances on April 18, 1936.

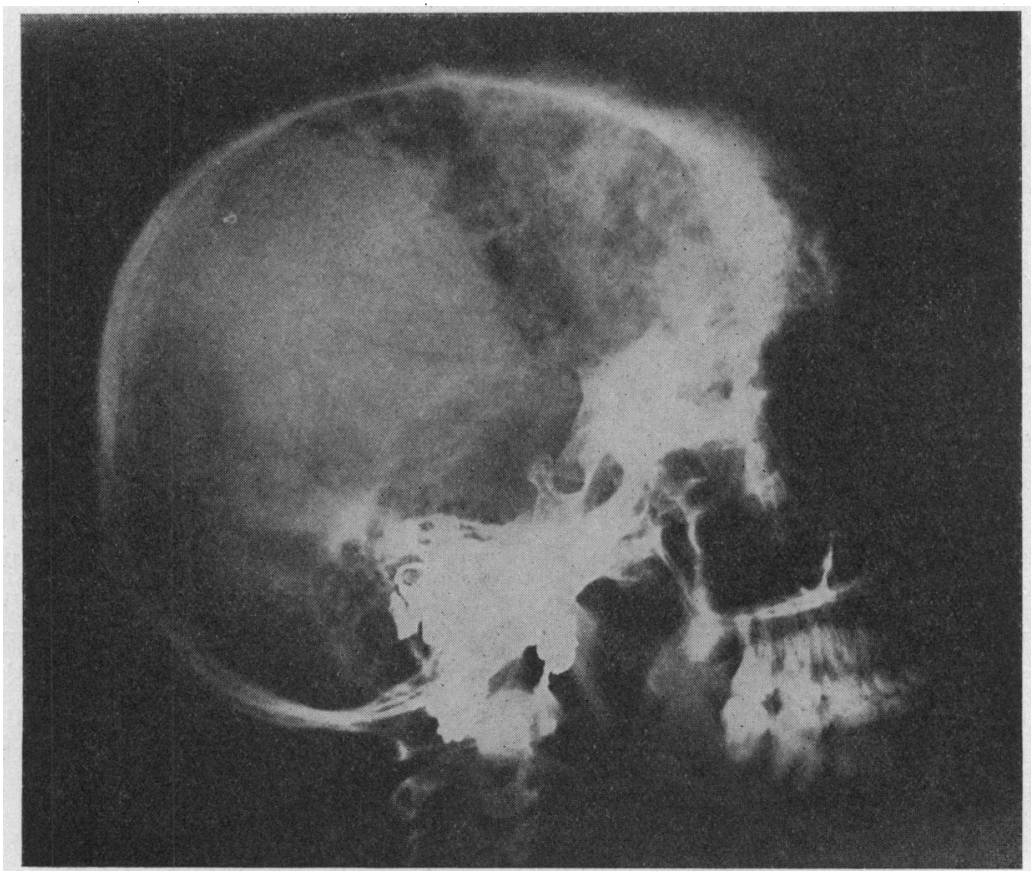

FIG. 3. 
depression in the superior temporal quadrant of the orbit of relatively small size. The proptosis was relieved. At the time of operation suitable portions of the bony tissue were fixed for histopathological examination.

The X-ray appearances of the skull and the state of the bone at the time of operation suggested a diagnosis of Paget's osteitis with cyst formation, or some fibro-cystic condition of bone related to the osteitis fibrosa group. Further investigation favoured a Paget's osteitis although certain features are not in accord with what may be regarded as the accepted picture. Other points in the patient's record may be summarised briefly.

General.- The patient appeared to be in good health and was nursing a healthy baby a few months old. A year later they were both still in excellent condition.

$X$-ray examination.-With the exception of the changes in the skull the skeleton appeared normal in every respect. A complete examination was made on two occasions, March, 1935, and April, 1936. No obvious change in the skull at this time, nor yet in any other part of the skeleton.

Blood chemistry and urine.-Calcium $12.6 \mathrm{mgs}$. per 100 c.c. (on two occasions). Inorganic phosphate 3.45 mgs. per 100 c.c. serum. No Bence Jones protein or albumen in urine. The blood picture showed a definite lymphocytosis in March, 1935, but was within normal limits a year later.

The percentage of haemoglobin was 70 and 60 respectively on these occasions.

Histopathology.-Report by Dr. T. Bhaskara Menon, Pathologist, Stanley Medical School, Madras :-

"There is an invasion of the bone by a fibroblastic tissue, which shows here and there a few osteoblasts. There is absorption of the lamellae and rarefaction. The fibroblastic invasion is similar to that found in osteitis fibrosa cystica. The appearances vary somewhat in different portions of the tissue. In one preparation, the bony lamellae are separated by fibrous tissue showing well marked fibrocytes with collagen fibres. In places the fibrous tissue appears to be hyaline, the blood vessels few. Rarefaction is met with in some places. Another preparation shows rarefied bony lamellae in one area, with fibro-vascular tissue in the adjoining one. The fibro-vascular tissue shows areas of haemorrhage and perivascular infiltration with lymphoid and mononuclear cells. There are numerous fibroblasts besides well formed fibrous tissue. In a third the fibro-vascular inflammation of bone seems to be the predominant change. In addition there are extensive areas of haemorrhage."

The histopathology is consistent with the view that this is an instance of a localised fibrocystic disease of bone, falling within 
the group in which there is no change in the calcium and phosphate metabolism, in contradistinction to the more generalised or diffuse fibrocystic disease with multiple bone cysts, hyperparathyroidism, altered calcium and phosphorous values in the blood stream, the former raised, the latter lowered. In view of modern work on the " osteitis fibrosa" group it might be better perhaps to avoid the names of Paget and von Recklinghausen until with improved classification of bone diseases, they can be attached to definite types without adding to the confusion which even now exists.

\title{
ACUTE DACRYOADENITIS DUE TO THE MORAX-AXENFELD DIPLOBACILLUS
}

BY

\author{
LT.-COL. R. E. WRIGHT, C.I.E., I.M.S. and \\ RaO Bahadur DR. K. Koman Nayar \\ GOVERNMENT OPHTHALMIC HOSPITAL, MADRAS, INDIA
}

IN July, 1936, Dr. N. Pillai drew our attention to a run of three cases of acute dacryoadenitis which he had seen in the out-patient's department of this hospital within a few weeks and asked our opinion as to their nature. In two of them a few small subconjunctival beads of pus showed over the region of the accessory gland; otherwise they all subsided without suppuration. The condition is ordinarily very uncommon, and as the aetiology was in doubt it was determined to make cultivations from the enlarged preauricular gland of the third case on a variety of media which usually favour the growth of the conjunctival flora. The media were those found most satisfactory by Dr. B. P. B. Naidu, of the Medical Research Department of the Government of India, when investigating the normal and pathogenic conjunctival flora in this hospital in 1935-36 while collaborating in trachoma research.

Short clinical note.-The patient, a Hindu boy, aged 19 years, first felt pain at the right inner canthus on July 26, 1936, five days before admission. Next morning his upper lid was red, swollen and tender. $\mathrm{He}$ had photophobia and lacrymation, tenderness in front of the ear and slight fever. On coming to hospital, there was chemosis of the bulbar conjunctiva, swelling in the superior temporal quadrant of the orbit with pain and tenderness. The swelling projected into the conjunctival fornix in the superior temporal region, giving the impression of an acute adenitis of the whole gland. The accessory gland was visibly inflamed. The cornea was clear. There was no discharge. It is regrettable that smears and cultures were not made from the 